\title{
Examining the evolution and convergence of wood modification and environmental impact assessment in research
}

\author{
Michael Burnard ${ }^{(1-2-3)}$, \\ Marko Posavčević (4), \\ Edo Kegel ${ }^{(5)}$
}

\begin{abstract}
We performed a bibliometric analysis of peer-reviewed publications on wood modification and environmental impact assessment of wood retrieved from the Scopus ${ }^{\circledast}$ database. We used data mining and network analysis tools to investigate the development of the field over time. We explore both wood modification and environmental impact assessment separately, and investigate where the publication record overlaps. Our research revealed that in recent years both topics have produced sharp increases in the number of publications, and have diversified greatly in recent years. Additionally, there were differences in the author collaboration patterns between each field. Fewer authors have contributed over a longer period of time in the wood modification publication record, whereas more authors have contributed over a shorter period of time to the environmental impact assessment of wood record, but they tend to collaborate less frequently. These methods allow researchers and industry members to quickly explore trends in research topics, the number of publications, where research is being conducted, and the growing network of researchers publishing together.
\end{abstract}

Keywords: Bibliometrics, Data Mining, Network Analysis, Wood Modification, Environmental Impact Assessment, COST Action FP1407, Wood

\section{Introduction}

Wood modification research and use has a long history, dating back to the early part of the $20^{\text {th }}$ century (Hill 2011). Over time, methods have been developed, have changed, have become industrialised, and our models for understanding them have also changed. Recently, environmental impact assessment has been utilised to analyse processing technologies and products, to optimise them, and to compare technologies and products in terms of their environmental performance. Organised efforts to merge these fields, such as COST
Action FP1407, "Understanding wood modification through an integrated scientific and environmental impact approach," exemplify this trend and provide a forum for researchers from across the globe to align their efforts, extend their capabilities through collaboration and learning, and share their work. The results of efforts like FP1407 should be evident in the publication record, in addition to other impacts. While it is early in the activities of FP1407 we can see participants presence in the publication record already, and identify researchers that could contribute to and ex-

(1) University of Primorska, Andrej Marušič Institute, Muzejski trg 2, 6000-Koper (Slovenia); (2) Renewable Materials and Healthy Environments Research and Innovation Centre of Excellence (InnoRenew CoE), Livade 6, 6310-Izola (Slovenia); (3) Abelium, d.o.o., research and development, Kajuhova ulica 90, 1000-Ljubljana (Slovenia); (4) University of Primorska, Faculty of Mathematics, Natural Sciences and Information Technology, Glagoljaška 8, 6000Koper (Slovenia); (5) Edo Kegel Consultancy \& Advice, Veerpoortwal 20, 6981BS Doesburg (The Netherlands)

@ Michael Burnard (michael.burnard@iam.upr.si)

Received: Feb 03, 2017 - Accepted: Aug 05, 2017

Citation: Burnard M, Posavčević M, Kegel E (2017). Examining the evolution and convergence of wood modification and environmental impact assessment in research. iForest 10: 879-885. doi: 10.3832/ifor2390-010 [online 2017-11-06]

Communicated by: Giacomo Goli

pand the Action's network.

Bibliometric analysis using network analysis and data mining techniques can reveal a great deal about the development of a field over time (Deville \& Stevenson 2015). Not only can these tools provide a broad overview of a field, researchers can utilise them to identify collaborators and research gaps, select journals, and predict trends. Co-word analysis is a basic data mining technique that finds patterns in word use to identify and highlight the structure of themes and ideas and the relationships between them (Whittaker et al. 1989, He 1999). Co-author analysis examines the joint work authors have completed together to form affiliation and collaboration networks. These tend to show genuine professional connections, as co-authorship is a formal arrangement, making it useful to identify strongly and weakly linked members of the research community (Newman 2001). A co-author network may show how single authors influence the growth of a field through many collaborations, or how isolated groups of authors tend to collaborate amongst themselves. This information can help to strategically identify new collaborators, either to collaborate with a strong, highly impactful author or to bring isolated groups of researchers into the major component of the network. Co-word and co-author analysis are well suited to network mapping and 
Tab. 1 - Search phrases used to retrieve both data sets.

\begin{tabular}{ll}
\hline Wood Modification & Environment impact assessment \\
\hline TITLE-ABS-KEY( & TITLE-ABS-KEY( \\
\{wood modification\} OR & \{wood OR timber) AND \\
\{modified wood\} OR & "“environmental impact assessment" OR \\
\{densified wood\} OR & "life cycle assessment" OR \\
\{wood densification\} OR & "life cycle costing" OR \\
\{timber modification\} OR & "environmental product declaration" OR \\
\{modified timber\} OR & "LCA" or “LCC" or "EPD” OR \\
\{densified timber\} OR & "carbon footprint" OR “carbon storage”)) \\
\{timber densification\} OR & AND KEY (NOT soil OR logging) \\
((wood OR timber) AND & \\
(\{therm* modif*\} OR & \\
\{hy?ro* modif*\} OR & \\
\{mechan* modif*\})) OR & \\
((wood or timber) AND & \\
(\{therm* treat*\} OR \{ & \\
hy?ro* treat*\} OR & \\
\{mechan* treat*\} OR & \\
\{heat treat*\}))) & \\
\hline
\end{tabular}

analysis, which is particularly useful when used to visualise, model, and inspect the structure of affiliations between individuals or topics (e.g., an affiliation network with a large number of single-to-many and many-to-many relationships - Persson \& Beckmann 1995, Newman 2001).

Our objectives were to:

1. determine if and how the research focus of wood modification has changed over time;

2. determine if and how the research focus of wood environmental impact assessments have changed over time;

3. determine the extent environmental impact assessment is implemented in wood modification research;

4. develop and examine co-author and coword networks in both fields;

5. identify collaborative efforts between countries in COST Action FP1407.

Tab. 2 - Summary of cleaned publication records for each topic, and those publications appearing in both datasets. $(*)$ : The total number of journals, proceedings, books, etc. uniquely appearing in the data; $(* *)$ : the resulting data for this section includes only those records that are present in both primary datasets.

\begin{tabular}{lr}
\hline Topic & N \\
\hline Wood Modification & 922 \\
- Authors & 1775 \\
- Journals/Publication outlets* & 278 \\
- Earliest publication & 1955 \\
Environmental Impact & \\
Assessment of Wood & 695 \\
- Authors & 1833 \\
- Journals/Publication outlets* & 274 \\
- Earliest Publication & 1977 \\
Appearing in both datasets* & -- \\
- Articles & 5 \\
- Authors & 86 \\
- Journals/Publication outlets* & 61 \\
\hline
\end{tabular}

\section{Methods}

This research closely follows the methods proposed by Deville \& Stevenson (2015) performing bibliometric analysis of ceramics research. Our examination covers two primary datasets - one for each topic - extracted from the Scopus ${ }^{\circledR}$ document search provided by Elsevier B.V. The search phrases for the wood modification dataset are provided in Tab. 1, and for environmental impact assessment of wood in Tab. 1 (nb.: the "?" in "hy?ro" matches both "hydro" and "hygro"). The datasets were a collection of information about academic papers, books and book chapters, conference papers, and reviews. The data included authors, institutions, titles, keywords, and abstracts, amongst other identification data (e.g., DOls and other bibliographic identification). These datasets were reviewed manually to identify and remove duplicates and false positive results (e.g., those that were off-topic), adjust author names of various configurations (e.g., to equate Burnard, M.D. with Burnard, M.), and to expand abbreviations (e.g., to equate JPN and Japan), amongst other similar procedures. Spelling was normalised to British English (e.g., fiber becomes fibre). In removing false positives, we erred on the side of inclusion in the dataset keeping all instances where titles, keywords, and abstracts presented some notable relationship to the topics of interest. The environmental impact assessment dataset resulted in more false positives. Topics most frequently removed from the dataset were forestry (and not wood products) related papers, and papers examining the lignin carbohydrate complex, which is often abbreviated "LCC" and shares an abbreviation with life cycle costing.

Data set preparation included removing stopwords (e.g., and, the, with) and joining similar words (merging singular and plural versions, conjugations, etc.). Topical adjectives were also merged (e.g., thermal and thermally, or treated, treating, and treat- ment). Multiple word keywords were also merged (e.g., thermal modification becomes thermal-modification) to more accurately account for different processes.

Word and topic frequencies were normalised by year to account for increasing number of publications per year and are fractions of the total record count for a given year.

COST FP1407 participants are considered here if they are Management Committee members or have contributed to an abstract published by the Action.

Data preparation and network analysis was conducted in R ( $R$ Core Team 2016) using the tm package (Feinerer et al. 2008) and in gephi (Bastian et al. 2009). Visualisations were made in R ( $R$ Core Team 2016) using the wordcloud2 (Lang 2016) and ggplot2 (Wickham 2009) packages and in gephi (Bastian et al. 2009) using the Fruchterman Reignold layout (Fruchterman \& Reingold 1991). The networks created and analysed are undirected, and give no preference to author order in publications. The vertices in network graphs represent individual authors, keywords, or countries and the edges represent the link between them (authors publishing together, or keywords appearing together). For example, if authors have published together, there will be an edge connecting their respective nodes. The size of vertices represents frequency of occurrences in the dataset. For example, an author with 10 records will have a larger vertex than an author with 5 records in the dataset. Similarly, edge weights increase as more examples of the indicated relationship occur in the dataset. For example, if the terms "thermal" and "colour" appear together as keywords 30 times in the dataset, they would have a heavier edge connecting their respective vertices than if they only had 15 co-occurrences.

Some concepts from graph theory and network analysis are useful for summarising complex networks such as those presented in this paper. We use "degree" to indicate the number of vertices a single vertex is connected to and "community" to mean a densely connected set of vertices. A community's "modularity" increases as the ratio of internal to external links increases.

The cleaned data sets, as well as the $R$ code to produce the analysis conducted in $R$, along with gephi network files are available on the figshare data repository (Burnard 2017).

\section{Results and discussion}

\section{Publication records}

After cleaning the Scopus ${ }^{\circledR}$ wood modification and environmental impact assessment of wood (EIAW) results yielded 922 and 695 records, respectively. Wood modification publications appear as early as 1955, while the earliest environmental impact assessment publications related to 
Tab. 3 - Summary information of articles published in both datasets.

\begin{tabular}{|c|c|c|c|c|}
\hline Title & Keywords & Year & Type & Reference \\
\hline $\begin{array}{l}\text { Integration of LCA in R\&D by applying the } \\
\text { concept of payback period: case study of a } \\
\text { modified multilayer wood parquet }\end{array}$ & $\begin{array}{l}\text { Flooring; GHG; NREU; Parquet; Payback; } \\
\text { Prospective LCA; Streamlined; Wood modification }\end{array}$ & 2017 & $\begin{array}{l}\text { Journal } \\
\text { article }\end{array}$ & $\begin{array}{l}\text { Hesser et al. } \\
2017\end{array}$ \\
\hline $\begin{array}{l}\text { Thermally modified timber: Recent } \\
\text { developments in Europe and North America }\end{array}$ & $\begin{array}{l}\text { Environmental product declarations; Low-carbon } \\
\text { bioeconomy; Product category rules; Sustainability }\end{array}$ & 2016 & $\begin{array}{l}\text { Journal } \\
\text { article }\end{array}$ & $\begin{array}{l}\text { Sandberg \& } \\
\text { Kutnar } 2016\end{array}$ \\
\hline $\begin{array}{l}\text { Wood acetylation: A potential route towards } \\
\text { climate change mitigation }\end{array}$ & $\begin{array}{l}\text { Acetylated wood; Carbon footprint; Climate } \\
\text { change mitigation; Green building; Greenhouse gas } \\
\text { emissions }\end{array}$ & 2014 & $\begin{array}{l}\text { Conference } \\
\text { proceeding }\end{array}$ & $\begin{array}{l}\text { Van Der Lugt \& } \\
\text { Vogtländer } 2014\end{array}$ \\
\hline Sustainable development in wood industry & Sustainable development; Wood industry & 2011 & $\begin{array}{l}\text { Conference } \\
\text { proceeding }\end{array}$ & $\begin{array}{c}\text { Kutnar \& Tavzes } \\
2011\end{array}$ \\
\hline $\begin{array}{l}\text { Chemical modification of timber decking: } \\
\text { Assessing the parameters of acceptability }\end{array}$ & $\begin{array}{l}\text { Acceptability; Chemicals; Industrial ecology; } \\
\text { Innovation; Wood }\end{array}$ & 2007 & $\begin{array}{l}\text { Journal } \\
\text { article }\end{array}$ & $\begin{array}{l}\text { Killerby et al. } \\
2007\end{array}$ \\
\hline
\end{tabular}

wood appeared in 1977. Overall, there were more publications in the wood modification records (922) than in the EIAW records (695). However, there were more authors contributing to EIAW publications. Only 5 publications appeared in both datasets, whereas 86 authors had contributed to publications in both datasets. The 86 authors appearing in both datasets contributed to articles outside of the 5 publications in both datasets (e.g., authors may have separately contributed articles appearing in each dataset). 61 journals/publication outlets appeared in both datasets. A summary of the publication record is presented in Tab. 2.

The publications appearing in both datasets cover topics ranging from thermally modified wood and acetylation to sustainable development in the wood industry (Tab. 3). In four of these articles, the main theme is sustainability through wood modification and the use of modified wood. In the other article, the main topic is sustainability through integration of life cycle assessment in RDI practices. The earliest publication appearing in both datasets is from 2007 , and the most recent is from 2017. There are four journal publications and three conference contributions in this dataset (Tab. 3).

\section{Wood Modification}

The number of wood modification publications released each year grows slowly until the early 1990's, when they started to grow more rapidly. Beginning around 2002 the number of wood modification publications began to increase drastically increasing from 15 per year in 2002, to 105 publications related to wood modification in 2016 (Fig. 1a).

With the increase in publications and authors contributing, the topics covered in wood modification publications evolved. With the broadening of topics, new methods were employed to modify wood and characterise the resulting products. To examine the evolution of keyword usage over time, the relative occurrence of selected keywords over time were investigated (Fig. 1b). The selected words were chosen based on their rank amongst the overall most used keywords which pro-

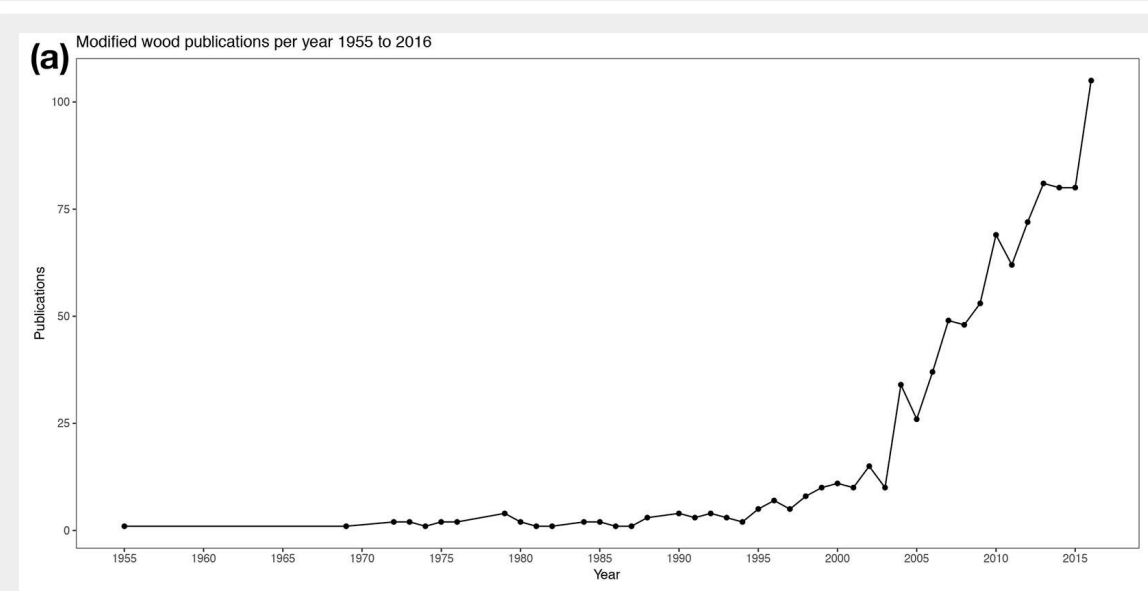

(b) Keyword occurrence in wood modification publications 1990 to 2016

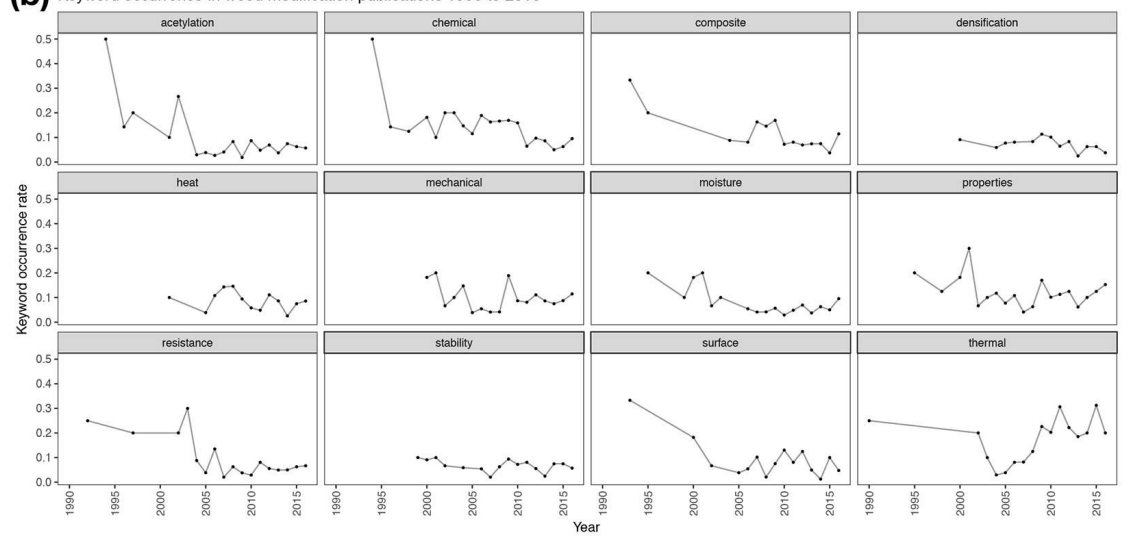

Fig. 1 - (a): Wood modification related publications per year. (b): Rate of occurrence of selected keywords in the wood modification publication record. (Burnard 2017).

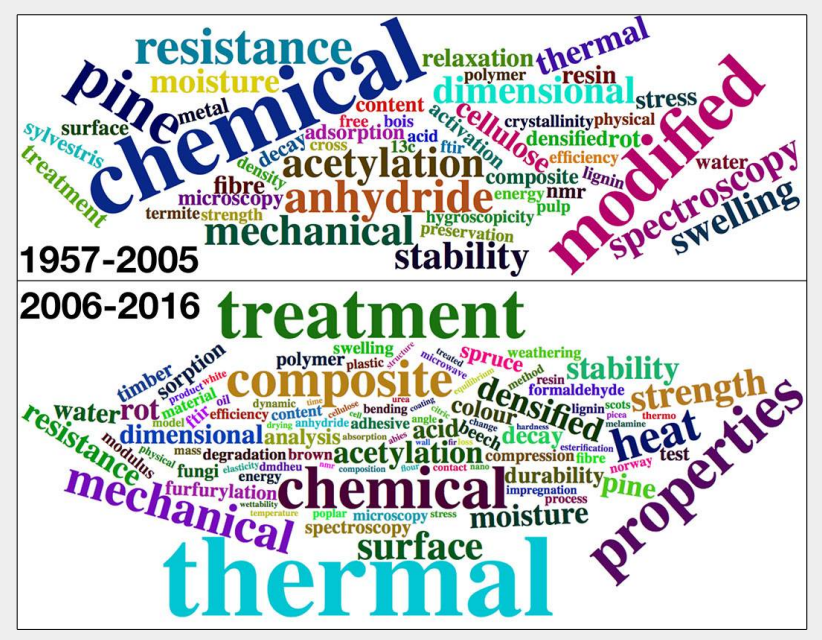

Fig. 2 - (A): Wood modification keywords word cloud, 1955 to 2005 (3 or more occurrences). (B): Wood modification keywords word cloud, 2006 to 2016 (10 or more occurrences). Size of word indicates relative frequency of occurrences in the dataset (Burnard 2017). 


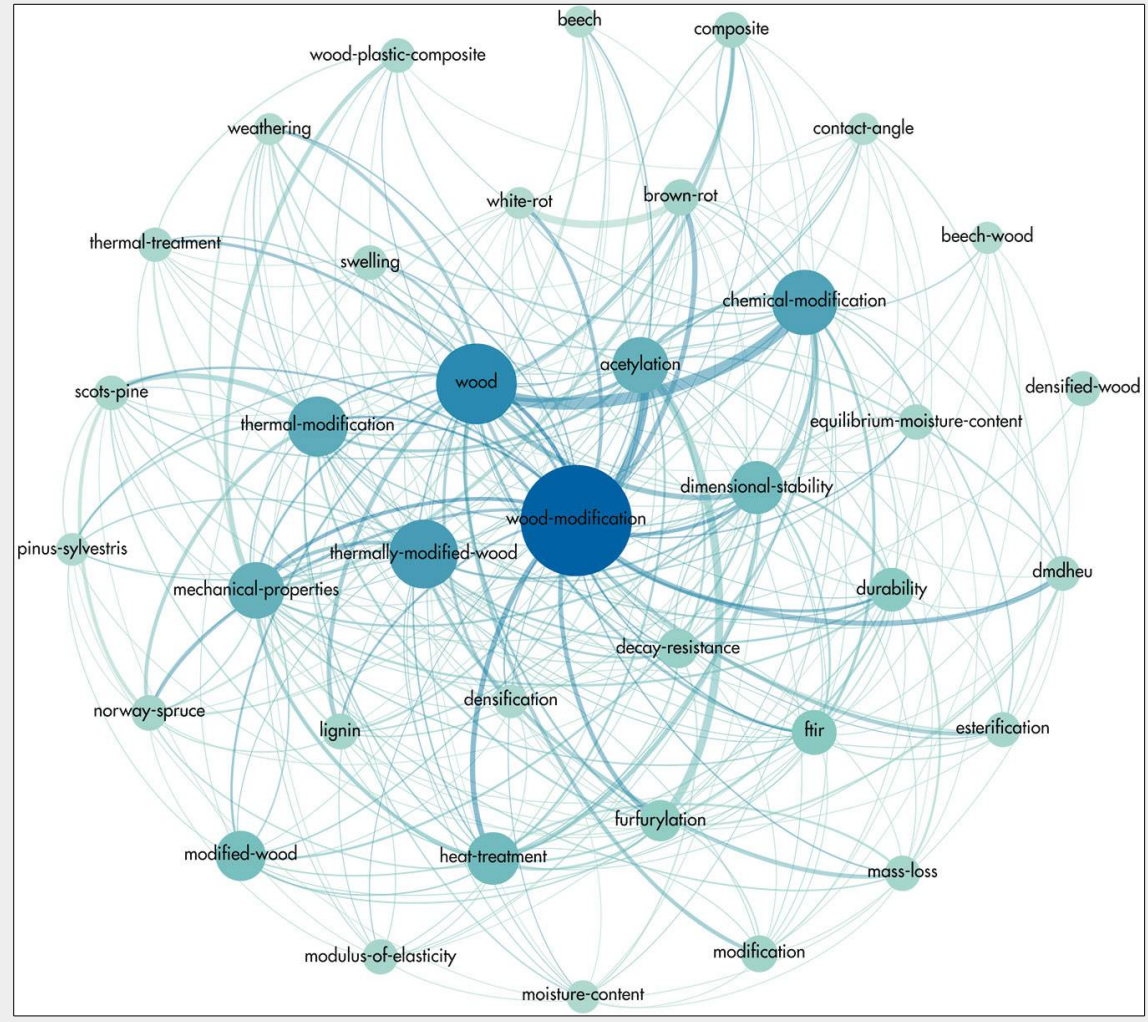

Fig. 3 - Wood modification keyword co-word network. Node size indicates its degree (the number of other nodes it is connected to, and also indicates frequency of word occurrence); edge width indicates frequency of co-occurrence. Only nodes with degree 45 or greater are included to simplify the image. Includes all publications in the dataset (Burnard 2017).

(a) EIAW publications per year 1977 to 2016

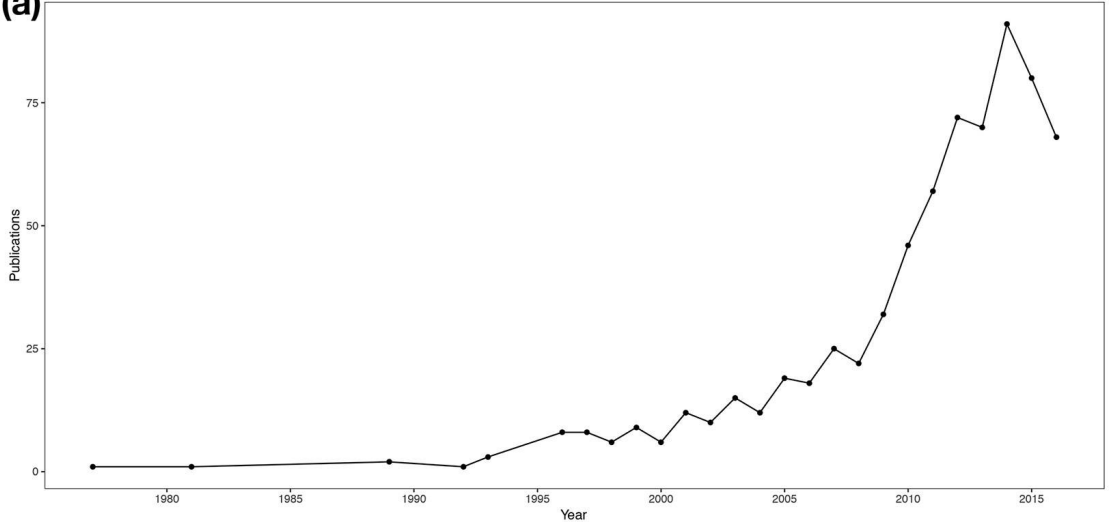

(b)

(b) Keyword occurrence in ElAW publications 1995 to 2016

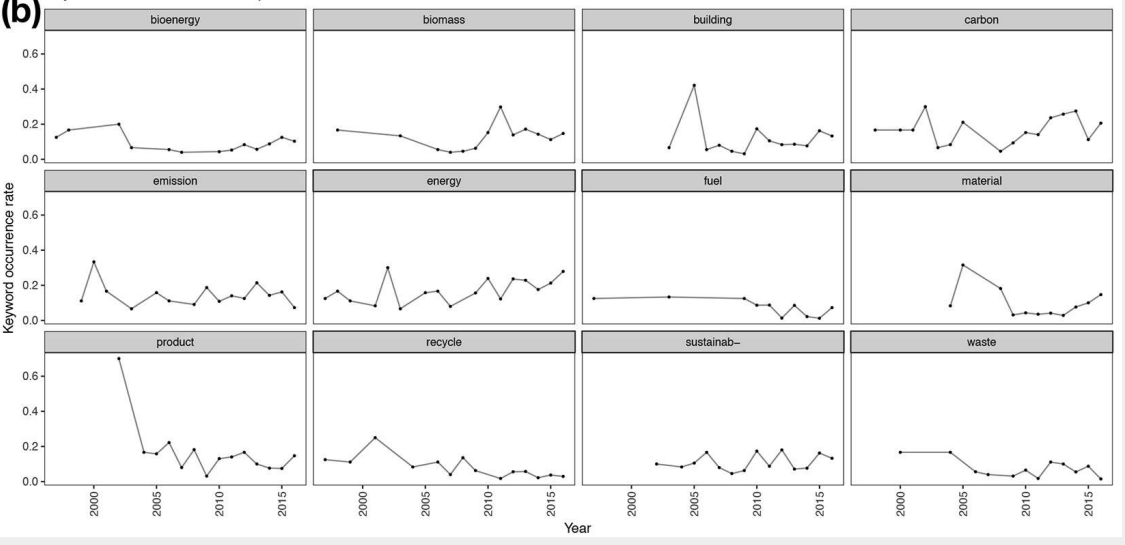

Fig. 4 - (a): EIAW related publications per year. (b): Rate of occurrence of selected keywords in the EIAW publication record. (Burnard 2017). vided some insight into topics of interest (e.g., "wood" and "modification" were excluded). As the diversity of topics examined related to wood modification increased, the relative rate of occurrence of any individual keyword is expected to decrease. However, the keyword "thermal" is a notable exception and has been used increasingly in since 2005 (1 publication) to 21 publications in 2016. Though publications covering "acetylation" (along with "chemical") modifications seem to have sharply declined, the actual number of papers per year has increased.

Bibliometric analysis can reveal these changes broadly, and is useful for investigating trends more specifically as well. Comparisons between word clouds of the most frequently used keywords from 1955 to 2005 , and for 2006 to 2016 indicate a clear increase in the number of papers examining thermal-related topics, densification, and composites (Fig. 2).

Additionally, there is clearly an increase in the range of topics and methods publications have covered since 2006, revealed in Fig. 2 by the increase in the number of terms appearing in the cloud.

Another method to analyse keyword use are co-word networks. These networks show not only the occurrence of a given keyword, but also which words are used together (Fig. 3). The graph reveals several key points about keyword use:

- Normalising keyword use would provide clarity and may help other researchers identify publications of interest. For example, "thermal-modification", "thermaltreatment" and "thermally-modifiedwood" (potentially, "heat-treatment" as well) likely refer to the same topics, and are frequently used separately, dividing the publication record.

- Chemical and thermal modification remain the most frequently mentioned modification methods, though densification is frequently, and increasingly, discussed as well.

- The key properties most researchers seem interested in are dimensional stability (keywords: "dimensional-stability", "swelling") and durability (keywords: "durability" "decay-resistance", "whiterot", "brown-rot").

- A drawback to this type of analysis is that new topics may take a time to appear in a reduced network graph (for readability, Fig. 3 has been reduced to only contain nodes of degree 45 or higher).

It is notable that "service life" was not discovered among the keywords used in wood modification publications. It is expected that related standards in Europe will begin using this term in place of durability in a forthcoming update.

Author contributions and cooperation are also useful to analyse. Identifying which authors most frequently work together, communities of authors that are isolated from the main mass of authors, and identifying potential collaborators are all potential 
uses of network analyses. The wood modification network has a single identifiable core contributor, with many directly and indirectly connected contributors throughout the network (see Fig. S1 in Supplementary material for a network graph of co-authors). 12 authors have contributed more than 14 papers each, and a total of 265 publications, which accounts for $15 \%$ of all publications in the record (Tab. 2).

The average degree of the network is 4.6, indicating on average authors have collaborated with between 4 and 5 authors. There are also notable isolated communities which have significantly contributed to the publication record (see Fig S1 in Supplementary material). The isolated groups are of particular interest for organisations that wish to increase cooperation, such as COST Actions. Identifying these authors this way, and reaching out to them provides an opportunity to increase cooperation between all authors.

If the goal for a networking organisation is to increase cooperation between authors, identifying highly modular communities and inviting them to participate should be a high priority.

\section{Environmental impact assessment of wood}

As with wood modification, the number of EIAW publications has increased over time (Fig. 4a). Beginning around 2000, publications began to appear more and more frequently, until 2008 when the number of publications per year increased sharply, reaching 91 publications in 2014, then decreasing to 68 in 2016.

Comparisons between word clouds for the time periods 1977 to 2005 and 2006 to 2016 reveal a strong degree of diversification in keyword use (Fig. 5). There were 52 words with more than three occurrences in the 1977 to 2005 set, and 98 words with more than 10 occurrences in the 2006 to 2016 set.

As with wood modification, and as expected, as the number of publications expanded, so did the number of topics covered in EIAW publications. It is notable that standards seem to not have merited inclusion in many publications keyword lists. The most notable differences in keyword frequency between the two times periods are the increase in the appearance of the term "biomass" and the reduced emphasis on "paper". Changes in specific keywords over time reveal interesting points (Fig. 4b), for example:

- Buildings quickly became a topic of interest around 2005 and the topic continues to be frequently discussed in the publication record.

- "Biomass" has been mentioned in the publication record since the late 1990's, and after an apparent peak around 2011, remained an important topic.

The keyword co-word network reveals how fractured the use of descriptive terms about environmental impact assessment is

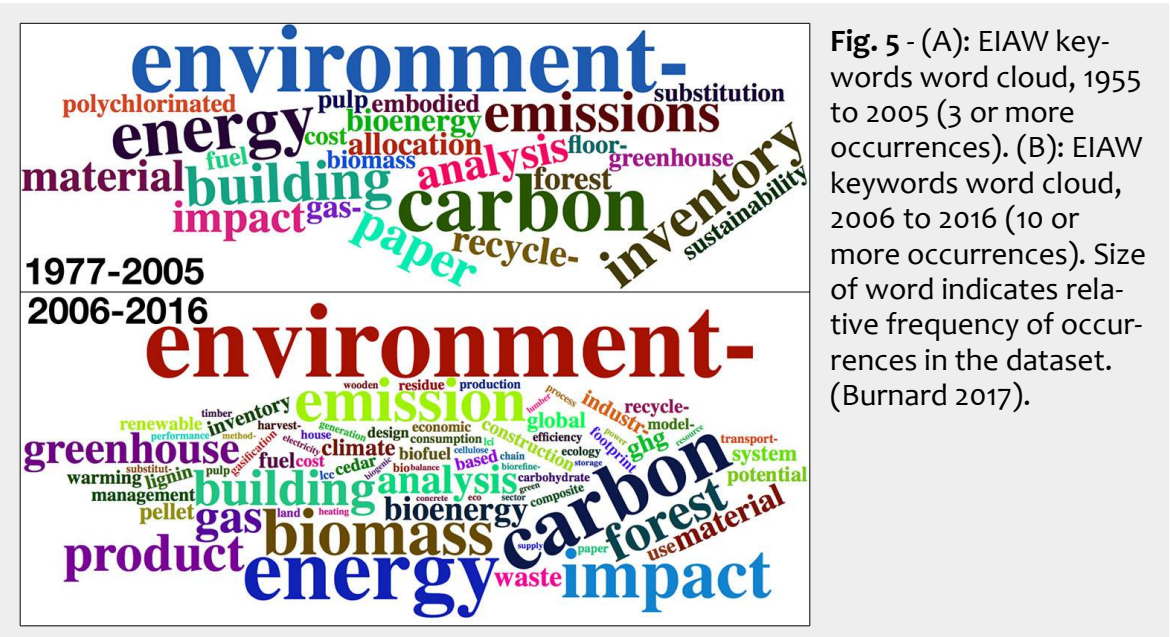

in the keyword record (Fig. 6). Terms including, "environmental-impact-assessment", "environmental-impact", "carbonfootprint", "environmental-performance", amongst others, may refer to the same processes or outcomes. However, the frequency with which these terms occurs independently obfuscate other relevant terms, especially the topics of the assessments in question.

The co-author network for EIAW differs in two key ways from the wood modification

co-author network. First, the network is more loosely connected and has more communities with higher modularity (more isolated groups - see Fig. S2 in Supplementary material for a network graph of EIAW author collaboration). Second, there are three authors at the centre of the network that frequently collaborate. The average degree of this network is 3.1, indicating authors collaborate with fewer authors than in wood modification, on average (see Fig S2 in Supplementary material). Thirteen au-

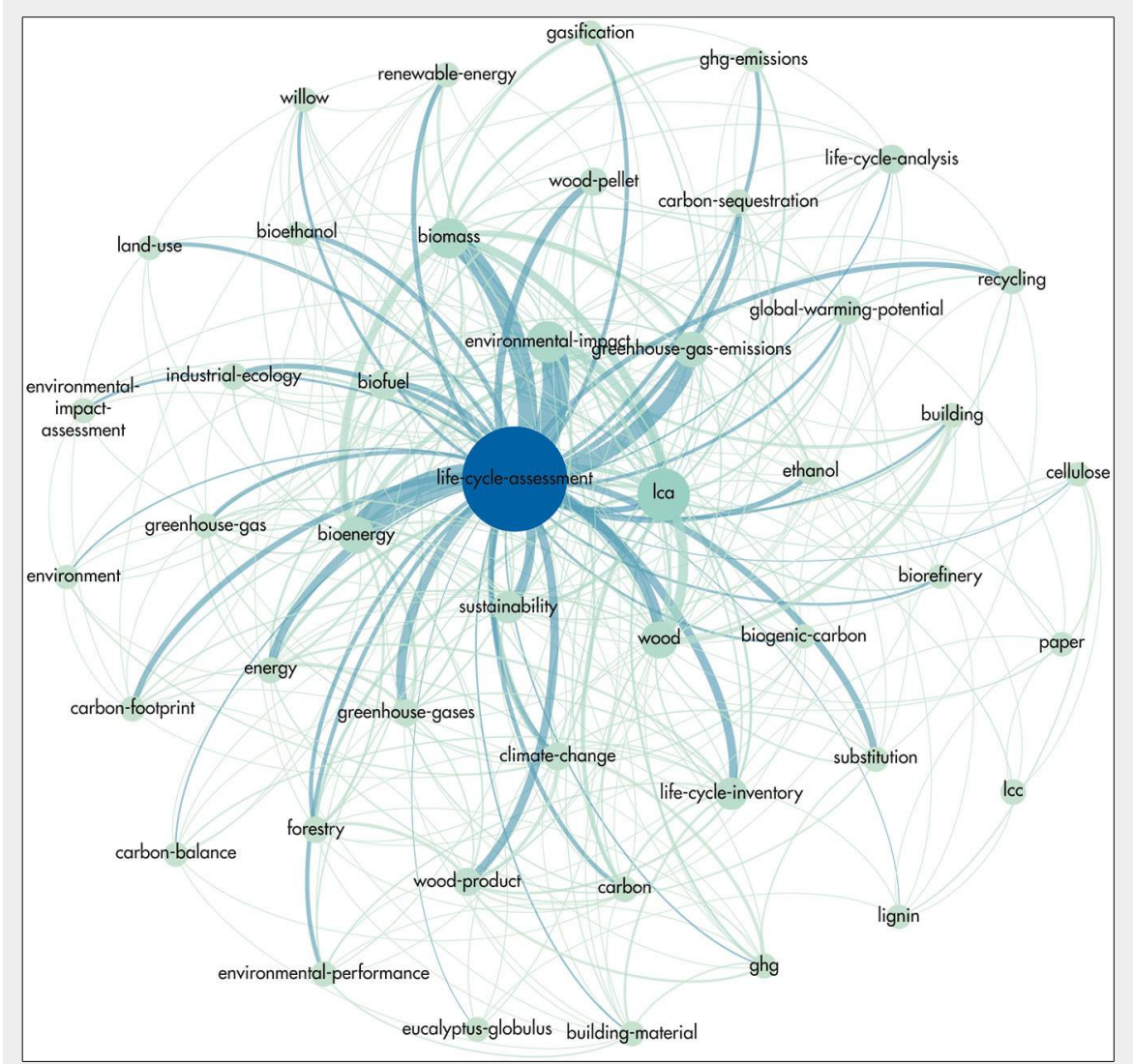

Fig. 6 - Wood modification keyword co-word network. Node size indicates its degree (the number of other nodes it's connected to, and also indicates frequency of word occurrence); edge width indicates frequency of co-occurrence. Only nodes with degree 45 or greater are included to simplify the image. Includes all publications in the dataset (Burnard 2017). 
Tab. 4 - The 12 and 13 authors with the most contributions to the wood modification and environmental impact assessment of wood records, respectively. The number of displayed authors was selected to break between changes in the number of publications.

\begin{tabular}{lclc}
\hline Wood Modification & & \multicolumn{2}{l}{ Environmental Impact Assessment } \\
\hline Name & Publications & Name & Publications \\
\hline Militz, H. & 59 & Feijoo, G. & 19 \\
Mai, C. & 38 & González-García, S. & 19 \\
Hill, C.A.S. & 23 & Moreira, M.T. & 18 \\
Cao, J. & 20 & Richer, K. & 13 \\
Kutnar, A. & 18 & Werner, F. & 9 \\
Rautkari, L. & 18 & Lippke, B. & 8 \\
Kamke, F.A. & 16 & Steubing, B. & 8 \\
Li, J. & 16 & Weber-Blaschke, G. & 8 \\
Hughes, M. & 15 & Gabarrell, X. & 7 \\
Brischke, C. & 14 & Beauregard, R. & 6 \\
Westin, M. & 14 & Kutnar, A. & 6 \\
Xie, Y. & 14 & Linder, M. & 6 \\
- & - & Strømman, A.H. & 6 \\
\hline
\end{tabular}

thors have contributed 6 or more publications, for a total of 133 publications (7\% of the EIAW records - Tab. 4). Extending the set to 5 or more publications expands the list of contributors to 30 authors.

\section{COST Action FP1407}

Through 2016, COST Action FP1407 has published two proceedings with a total of 76 extended abstracts. These proceedings include contributions from 31 countries. In some cases, these publications are early vehicles for newcomers to either, or both, of the fields. The network graph for coop-

eration between countries reveals France most frequently collaborates with other countries in the COST Action FP1407, and has a strong record of cooperation inside and outside of Europe (Fig. 7). In this case, network analysis presents an opportunity to explore, visualise, and gauge the success of the action in terms of its goal to enhance cooperation and collaboration in the field of the Action. Other goals, especially related to COST inclusiveness countries can also be gauged through this method quickly, while also revealing which collaborations have enhanced inclusivity.

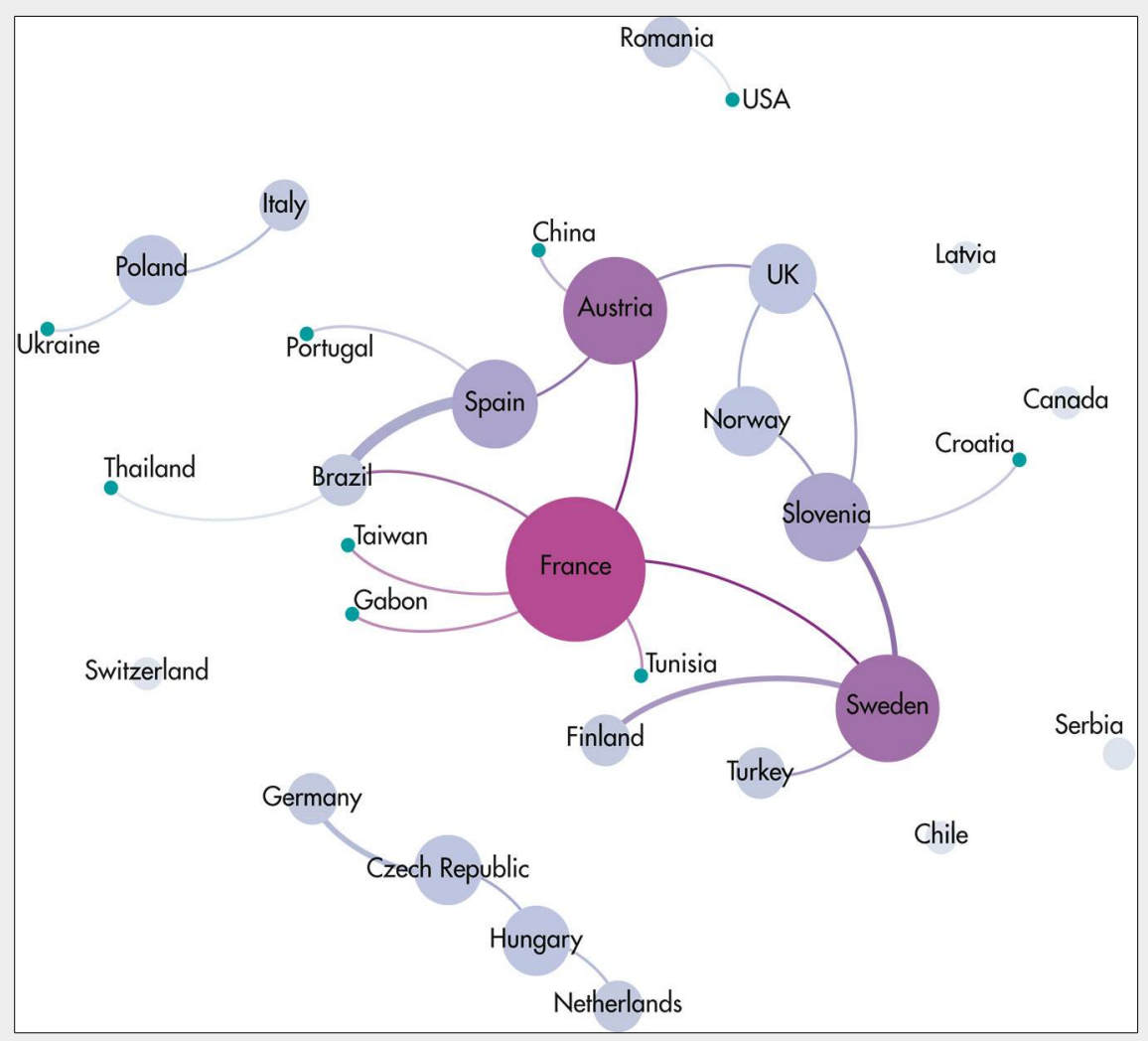

Fig. 7 - Country collaboration network for contributions to COST Actions FP1407's two published proceedings (Burnard 2017).

\section{Conclusions}

Bibliometric analysis of publications in a particular field presents an intriguing method for exploring a field as a whole, its development over time, and provides researchers with a means to identify knowledge gaps and collaborators. In this paper, we examined two subsets of wood science research: wood modification, and environmental impact assessment of wood. In our analysis, we clearly see an expansion of modification methods beyond the early chemical and impregnation methods that dominated the field early on. As this shift occurs in wood modification publications, environmental impact assessment begins to become a common tool amongst wood science researchers in general, and this trend is evident in the subset of researchers working on wood modification as well. As concerns about environmental impacts continue to be a major part of political, scientific, and public discourse, researchers will continue to look for ways to mitigate them, and analyse the effectiveness of their mitigations. 86 authors appear in both of the wood modification and EIAW datasets, indicating significant number of authors participate in both wood modification research and environmental impact assessment. COST Action FP1407 presents an example of how these fields can be enhanced through an organised network of practitioners that encourages collaboration, sharing, and continued learning in two connected but different disciplines. Network analysis provides a means of gauging the Action's success, as well.

To make publications easier to find and categorise authors should carefully select keywords. Searching for and selecting existing keywords that are used frequently (and accurately represent the article) will increase the visibility of publications and enhance efforts to analyse the field whether through bibliometric analysis or through conventional reviews. Normalising how authors refer to terms with common abbreviations and various phrasings will also help. This is especially notable in how authors refer to greenhouse gas emissions, which appear in the dataset as: "ghg", "ghg emissions", "greenhouse gases", "greenhouse gas emissions", and "green house gas emissions". The burden of creating easily findable publications does not rely entirely on the author. Indeed, repositories and indexing services (such as the ISI Web of Science ${ }^{\circledast}$ ) could improve access to bibliometric data through an application programming interface (API) that provided modern query access. Ideally, the API would allow automated and iterative searches of the publication record. Open access publication is another important aspect of the growth of bibliometric and data mining techniques. With free access to the full text of the publication record, the body of the text could be analysed more deeply without fear of violating copyright. 
Many articles had no associated author keywords readily available (either in the publication record, or when reviewing the actual articles). This was surprising, and seemed to be associated with specific journals. Keywords are an important part of this type of analysis, and quickly being able to distinguish topics and relevance based on keywords remains a useful tool for identifying and, importantly, promoting an article to interested audiences.

Network analysis is an intriguing method for exploring any topic where multiple linked entities are of interest. Its usefulness is extended in an interactive environment, however, where researchers can quickly explore, analyse, and learn about a topic by gaining information about specific nodes, edges, and clusters dynamically.

\section{Acknowledgements}

The authors acknowledge COST Action FP1407. The authors further acknowledge the support of WoodWisdom-Net + and the Slovenian Ministry of Education, Science, and Sport of the Republic of Slovenia for their support of the Cascading Recovered Wood project; the European Commission for funding the InnoRenew CoE project (\#Grant Agreement 739574) under the Horizon2020 Widespread-Teaming program, and the Slovenian infrastructure program IP-0035.

\section{References}

Bastian M, Heymann S, Jacomy M (2009). Gephi: an open source software for exploring and manipulating networks. In: Proceedings of the " 3 rd International ICWSM Conference". San José (CA, USA) 17-20 May 2009. Association for the Advancement of Artificial Intelligence, pp. 361-362. [online] URL: http://www.aaai.org/ocs/ index.php/ICWSM/og/paper/view/154
Burnard MD (2017). Wood modification and environmental impact assessment of wood bibliometric analysis R file. Web site. - doi: $10.6084 /$ m9.figshare. 4596100

Deville S, Stevenson A (2015). Mapping ceramics research and its evolution. Journal of the American Ceramic Society 98 (8): 2324-2332. - doi: 10.1111/jace.13699

Feinerer I, Hornik K, Meyer D (2008). Text mining infrastructure in R. Journal of Statistical Software 25 (5): 1-54. - doi: 10.18637/jss.v025.io5

Fruchterman T, Reingold E (1991). Graph drawing by force directed placement. Software: Practice and Experience 21 (11): 1129-1164. - doi: 10.1002/spe.4380211102

He Q (1999). Knowledge discovery through coword analysis QINHE. Library Trends 48: 133159.

Hesser F, Wohner B, Meints T, Stern T, Windsperger A (2017). Integration of LCA in R\&D by applying the concept of payback period: case study of a modified multilayer wood parquet. The International Journal of Life Cycle Assessment 22 (3): 307-316. - doi: 10.1007/s11367-016$1173-y$

Hill CAS (2011). Wood modification: an update. BioResources 6 (2): 918-919. [online] URL: http://ojs.cnr.ncsu.edu/index.php/BioRes/article /view/BioRes_06_2_0918

Killerby S, Maplesden F, Jack M, McDonald G, Rolland D (2007). Chemical modification of timber decking: assessing the parameters of acceptability. New Zealand Journal of Forestry Science 37 (3): 412-434. [online] URL: http:// www.researchgate.net/publication/290291701

Kutnar A, Tavzes C (2011). Sustainable development in wood industry. In: Proceedings of the $22^{\text {nd }}$ International Scientific Conference "Wood is Good - EU Preaccession Challenges of the Sector" (Grbac I, Mihulja G eds). Faculty of Forestry, University of Zagreb, Zagreb, Croatia, pp. 83-88. [online] URL: http://www.cabdirect. org/cabdirect/abstract/20113406442
Lang D (2016). wordcloud2: create word cloud by htmIWidget. Web site. [online] URL: http:// cran.r-project.org/package=wordcloud2 Newman MEJ (2001). Scientific collaboration networks. I. Network construction and fundamental results. Physical Review E 64:16131. doi: 10.1103/PhysRevE.64.016131

Persson O, Beckmann M (1995). Locating the network of interacting authors in scientific specialties. Scientometrics 33: 351-366. - doi: 10.1007/BF02017336

R Core Team (2016). R: a language and environment for statistical computing. R Foundation for Statistical Computing, Vienna, Austria. [online] URL: http://www.r-project.org/

Sandberg D, Kutnar A (2016). Thermal modified timber (TMT): recent development in Europe and North America. Wood Fiber Science 48: 2839. [online] URL: http://wfs.swst.org/index.php /wfs/article/view/2296

Van Der Lugt P, Vogtländer JG (2014). Wood acetylation: a potential route towards climate change mitigation. WIT Transactions on The Built Environment 142: 241-252. - doi: 10.2495/ ARC140221

Whittaker J, Courtial J-P, Law J (1989). Creativity and conformity in science: titles, keywords and co-word analysis. Social Studies of Science 19 (3): 473-496. - doi: 10.1177/030631289019003004 Wickham H (2009). ggplot2: elegant graphics for data analysis. Springer Verlag, New York, USA, pp. 260. [online] URL: http://ggplot2.org

\section{Supplementary Material}

Fig. S1 - Wood modification co-authors network.

Fig. S2 - EIAW co-author network.

Link: Burnard 2390@supplo01.pdf 